\author{
Articles \\ Daithí Kearney | Adèle Commins \\ Studio Trad
}

\title{
Studio Trad: Facilitating traditional music experiences for music production students 1
}

Daithí Kearney and Adèle Commins

Dundalk Institute of Technology

Ethnomusicologist, geographer and performer Dr Daithí Kearney is co-director of the Creative Arts Research Centre at DkIT. His research is primarily focused on Irish traditional music but extends to include performance studies, community music and music education. Daithí tours regularly internationally as a musician, singer and dancer with a number of groups including Siamsa Tíre, The National Folk Theatre of Ireland and as director of the DkIT Ceol Oirghialla Traditional Music Ensemble. He has contributed articles to publications in the areas of ethnomusicology, folklore and music education. Contact: Department of Creative Arts, Media and Music, Dundalk Institute of Technology, Dundalk, Co. Louth, Ireland. A91 K584.

E-mail: daithí.kearney@dkit.ie

ORCID: https://orcid.org/0000-0001-6304-3241

Musicologist Adèle Commins is Head of Department of Creative Arts, Media and Music at DkIT. Her main research interests focus on nineteenth- and twentieth-century English and Irish music, with a particular emphasis on the solo piano music of Charles Villiers Stanford. Other research interests include music editing and the scholarship of teaching and learning. She is an accomplished performer on piano, piano accordion and as a singer 
and is musical director of two local church choirs. She serves on a number of national committees including the Society for Music Education in Ireland National Committee and the RILM Ireland committee.

Contact: Department of Creative Arts, Media and Music, Dundalk Institute of Technology, Dundalk, Co. Louth, Ireland, A91 K584.

E-mail: adele.commins@dkit.ie

ORCID: https://orcid.org/0000-0002-5067-4930

\section{Abstract}

Many music production programmes in higher education institutions are heavily invested in popular music genres and production values in contrast to the diversity of musics often included in other music programmes and encountered in everyday life. Commenting on his 2017 album, Ed Sheeran highlights the potential for incorporating Irish traditional music into popular music. Over the past number of years, creative practice research projects at Dundalk Institute of Technology have provided opportunities for music production students to engage in the recording and production of Irish traditional music, broadening their experience beyond popular music genres and facilitating time for them to work collaboratively with Irish traditional musicians. Thus, an authentic and actionoriented mode of engagement in higher education is utilized to enhance the learning experience continuously aware of changes and attitudes in the music industry. This article focuses on three Summer Undergraduate Research Projects that provided students with the opportunity to research and record Irish traditional music during the summer months. The project not only provided the students with credible industry-like experience, it also 
provided the staff involved with an insight into the potential of collaborative project work to address multiple learning aims and objectives. In this article, a critical review of the projects is informed by feedback from the students involved, which can inform future development and structures of existing programmes in music production education. Keywords

Irish traditional music; undergraduate research; student-led research; music production education; practice-based research; collaborative learning

\section{Introduction}

Ed Sheeran was one of the most popular yet divisive artists of 2017, perhaps best attested by the reaction to his headline performances at Glastonbury (Ellen 2017; Petridis 2017) and his domination of the music charts (Halliday 2017; Snapes 2017). Undoubtedly Sheeran is one of the biggest pop stars in the world with an ability to dominate the charts and yet his approach to performance and production differs greatly from the paths taken by many others. Of interest here is his incorporation of Irish traditional music influences and the value of incorporating ethnomusicological studies of traditional musics into music production education. Reflecting as Irish traditional musicians working with students in the area of music production whose background is dominated by popular music culture, we consider the benefits of challenging the students through the use of other genres to widen their sound pallet and inform their learning experience. We focus on three recording projects that did, in one instance, lead to a commercial release.

The project aims were not about creating commercial success or new popular music but rather developing understanding amongst music production students in the area of Irish traditional music. It is not, as Sheeran stated in relation to his 2017 release Divide 
that '[t]rad should be at the forefront of pop culture' (Ganatra 2017) but rather that music production graduates have an understanding of different musical cultures and can ultimately recognize opportunities and be prepared for employment beyond the popular music sphere. Discourse in Irish traditional music has highlighted the potential for commodification and commercialization (Kearney 2012, 2013; O’Brien-Bernini 2016) and the challenges that this may present in terms of ownership (McCann 2001) and tourism ( Kaul 2007). However, there are opportunities for graduates of music production programmes to engage in the recording of various musical traditions and inform their artistry with reference to these traditions. As Guilbault notes, [t]he ethnicization of the mainstream forms of music that had become almost synonymous with the so-called 'global culture' can be viewed as both a sign and recognition that their historically privileged position is being challenged by the emergence of many other musics as well as networks of production of distribution.

(1993: 33)

There is an opportunity to take advantage of a world market now more accessible due to technology and distribution networks but this engagement with traditional musics should be informed by discourse in ethnomusicology.

To this end we are responding to Simon Zagorski-Thomas' calls for a musicology of record production that seeks greater understanding of cultural traditions, audiences and societies, and appreciation of aesthetics and collaborative creative practices. The projects outlined herein have a strong focus on the technical mastery of the recording process, from microphone selection through editing and mastering, but have another dimension that is informed by musicians and ethnomusicologists. Thus, the article presents a 'focus on the way people work in record production, rather than the way technology works' 
(Zagorski-Thomas 2014: 244). Indeed, Zagorski-Thomas' choice of Irish traditional music as the starting point for his penultimate chapter in The Musicology of Record Production (2014) is significant. In this chapter, he points to performance practices and spaces and how this can shape reception and the notion of authenticity. It is important for students to engage in the processes of music production beyond technology and gain a greater understanding of the aesthetic, social and cultural aspects of their art.

As well as engaging with teaching and learning developments at DkIT, the projects also address some of the challenges for the Irish music industry noted in the (2015) IMRO report on the socio-economic contribution of music to the Irish economy, particularly in relation to the lack of production expertise in Ireland. The development of the Irish government's Creative Ireland Programme 2017-2022 (2016) also challenges us to explore participation in creative activities and includes developing excellence in media production as one of five pillars.

\section{Educational philosophy}

The Department of Creative Arts, Media and Music at Dundalk Institute of Technology (DkIT) embraces a range of genres and approaches to the study of music with opportunities for collaborations with film and television and other technologies and media. The curriculum and the specific learning and assessment activities within the individual modules are designed to promote active, deep learning and understanding in line with a student-centred approach (Attard et al. 2010). An emphasis has been placed on the practical implementation of student learning through activities including performance practice, studio work and composition. Practical activities and projects are widely used throughout the programme to enable students to apply their knowledge to, 
and take more control of, their learning. As students progress through the course, they exercise choice in learning activities, assessments and modules, thus fostering more intrinsic motivation (Deci and Ryan 1985) and autonomous learning. Summer Undergraduate Research Projects (SURPs) provide opportunities for undergraduate students to further their learning in a largely independent manner with the support of a small stipend, mentorship and access to research facilities during the holiday period.

Feedback from music students at DkIT has highlighted a desire to gain industry experience and improve access to the facilities in the Institute in order to gain more experience with technology and processes. The value of experiential learning is widely acknowledged (Kolb 2014) and, in the context of music production education, Horning (2004: 705) cites Henry Seymour who states

[e]xperience, to be sure, is the only real teacher in the art of recording. There are so many subtleties to comprehend, so much mechanical finesse to grasp, that no written instructions could ever amount to more than a rough and ready guide. (Seymour 1918:

Mirroring some of the theories of David Elliott $(1995,2005)$ related to praxial music education, Merrill (2010) points to another benefit of music recording projects in the context of music education, memory and creativity, particularly amongst modern amateur recordists.

Authentic and action-oriented forms of engagement in higher education are increasingly recognized and utilized to enhance the learning experience (Lawson and Lawson 2013: 445-46). Music recording projects are an important aspect of the BA (Hons) Production of Music and Audio programme at DkIT. Often involving performers from the BA (Hons) Applied Music programme, alongside students on the production 
programme and external musicians, these projects lead to a diverse range of singles that reflect the diversity of sounds and production values in contemporary popular music. The value of a hands-on experience and opportunity to integrate theory with the practical aspects of the programmes underpins the ethos of staff on both programmes and are valued by the students. In years three and four of the programme, students engage in evening and Saturday recording sessions in which they gain access to Institute facilities to complete their projects. The summer music recording projects were initially developed by Dr Adèle Commins and Dr Daithí Kearney with a focus on Irish traditional music. In 2015 and 2016, three projects were developed with different research teams and outputs.

The Summer Undergraduate Research Programme at DkIT presents opportunities for students to gain experience in different areas of and approaches to research during the summer months. The programme also provides faculty with the opportunity to engage students in research projects that can help the development of curricula and approaches to teaching and assessment, as well as providing students with the opportunity to gain experience of research that can facilitate their transition from undergraduate to postgraduate study. There was also a desire to break down sub-discipline silos and broaden the education and research boundaries experienced by students in undergraduate programmes. Echoing the work of Gibbs (2009) but from a different perspective, the integration of ethnomusicological thought in music production raises questions related to the attitudes of performers, development of technology, changing listening practices and social contexts. The SURPs challenged the producers to engage in new analytical listening to evaluate "the context and the function of sound in relation to the musical or communication context in which it exists' (Moylan 2002: 90). Similarly, performance 
and ethnomusicology students were challenged to gain a greater understanding of the recording process and the technology used, as well as how that technology can play a role in shaping the sound of music for different audiences and in different contexts.

The three SURPs reviewed herein provided undergraduate students with the opportunity to research, rehearse and record Irish traditional music, requiring them to engage in different aspects of the process including the research of historical information and sources, the arrangement of music and the editing, mixing and mastering of recorded material. The projects not only provided the students with credible industry-like experience, they also provided the staff involved with an insight into the potential of collaborative project work to address multiple learning aims and objectives, which can inform curriculum development.

While the projects sought to encourage participants to develop self-directed learning and responsibility, the experience of the supervisory team was critical to the design and implementation of the project. In 2011, Daithí Kearney released the critically acclaimed album Midleton Rare with album design and related artwork by DkIT colleague J. J. Quinlan. Quinlan subsequently provided artwork for A Louth Lilt (2017), which resulted from one of the SURP projects, featuring the compositions and performances of Daithí Kearney and Adèle Commins. In his teaching and assessment, Quinlan has also engaged with the design of album covers with Creative Media students. Kearney is also the director of the DkIT Ceol Oirghialla Traditional Music Ensemble and has published widely in the area of Irish traditional music. Commins' recent recordings include tracks on the compilation albums Bunch of Keys (2014) and Journey to Your Heart (2015), and she also tours internationally and has completed extensive research on 
music in Ireland. Seán Keegan is both a performer and a producer, gaining notable recognition for his work with a variety of Irish traditional music artists. Thus, industry experience within the academic supervisory team was integral to the design and success of the projects.

One of the challenges for the project supervisors was to identify suitable candidates who would not only contribute to the project as strong individuals but whose skills and competencies would complement each other as part of a team. The supervisors recognized the importance of collaboration and the recognition that the recordist is a creative artist (Moylan 2002: 69) and the studio itself is a musical instrument (Thibeault 2012). Students on the BA (Hons) Applied Music and BA (Hons) Production of Music and Audio were invited to apply to participate in the projects, for which a stipend was funded through the DkIT Research Office. Applicants were required to submit a CV to the Research Office and they were evaluated by the proposed supervisory team, shortlisted and a selection was called for interview. The interview addressed motivation for participation, their experiences as performers in solo and group contexts, their skills as arrangers or composers, their competency as producers and studio engineers, and their ability to communicate ideas and work as part of a team. Students subsequently noted that the process of applying and undertaking an interview was beneficial to them, notably in the case of one student who was unsuccessful in the first year but successful in the second year.

The role of the supervisory team varied between projects, from being very handson as musicians guiding the production, to advisors at a distance who could provide 
technical advice or some critical feedback. Recognizing the involvement of staff, Evelyn noted:

[h]aving constructive feedback from lecturers and other outside people was very useful as sometimes they found or heard an issue with a track or alternatively they suggested methods to fix problems we were finding, particularly in the recording and production process. (Participant Feedback, 2015)

While staff were on hand throughout the duration of the project to offer advice, much of the work was student led.

A key aspect of the projects' success was the availability of and access to facilities with opportunities for learning through trial and error (Zagorski-Thomas 2014: 164). In her reflections on the Oriel Album Project, Evelyn noted:

[t]he facilities had a huge impact on the project. Because we had a huge amount of time in the studio it meant we were able to record a lot of material and listen back and roughly edit the recordings on proper speakers. We also had access to the computer labs which allowed us to use the computers for research, making weekly notes, compiling programme notes, completing research posters and notating source material utilising Sibelius notation software. (Participant Feedback, 2015)

One of the significant positive aspects of developing this project at DkIT was the availability of world-class facilities including access to performance practice and recital rooms, library, computer labs, audio-listening room, a state-of-the-art recording studio with five live rooms and associated control rooms, and various instruments including virtual instrument software. This contrasts with the assertion by IMRO (2015: 92) that Ireland lacks the necessary industry infrastructure to compliment the abundance of creative talent. The development of the BA Music and Audio Production and subsequent 
BA (Hons) Production of Music and Audio programmes augmented the offering at DkIT that already included music technology and production in the BA (Hons) Applied Music programme and an MA/MSc Music Technology. In an article espousing the benefits of recording studios for music education, Thibeault highlights the need to develop an understanding of the recording studio as a creative space, stating:

[w]hen one thinks of a recording studio, perhaps the first thing that comes to mind is the stuff' 'of technology - microphones, mixing consoles, computers, acoustic treatments, and instruments $[\ldots]$ But to think of a recording studio as merely a place for stuff leaves out the most important aspect, namely the professionals who work within studios and the wisdom they hold. [...] To think of the recording studio as a musical instrument is also to recognize that, over the past 100 years, studios increasingly play an active role as a creative space for music.

2012: 1)

Understanding the studio as a creative space also requires critical consideration of the producer as a creative artist. Reflecting on the somewhat limited understanding of a producer as a person focused on the technical and technological aspects of the recording process, Walzer (2015: 43) notes 'the creative decisions audio engineers make throughout the recording process' and their role in the realization of an album. In many instances, this relates not only to editing but also to the manipulation of sound. Horning states:

[e]ver since the earliest recordings, capturing a live performance on cylinder or disk required subtle manipulation of the recording equipment by the operator, even when there were few possibilities for manipulation. In fact, one can say there has never been a recording that did not require some intervention, although the degree of intervention varied widely, from a touch of 'echo' to assembling a recording from multiple edited performances. 
Examining the role of the music producer, Horning refers to the work of sociologist Edward Kealy (1974, 1979) who has documented the shifting status of sound mixers from craftsmen to artists:

[t]he changing technology, in particular multi-track recording, made it possible for recording engineers to become more involved in musical decisions made during recording, even as it enabled the music's creators to become more technical and in some cases to acquire a limited degree of engineering skill.

(Horning 2004: 715)

A significant part of this project was the development of an awareness of the potential of the studio as a creative space in which to capture and produce new sounds through various production processes, and the importance of creative collaboration in the recording process. The projects recognized clear roles for the recordist in the creative process, which further demanded good communication between all of those involved. As Zagorski-Thomas notes, 'the language of sound engineers and the language of musicians can sometimes not share common ground' (2014: 173). Thus the projects demanded a move away from silo mentality and the bringing together of students and staff who shape music learning from different perspectives. While participants had particular responsibilities in the projects as producers and performers, all were involved in the conceptualization and creative decision-making throughout the project.

\section{Project objectives}

Informed by both academic and industry contexts, three interconnected research objectives were identified and largely realized as part of the project. These relate to 
technical/production, musicological/ethnomusicological and music industry aspects of the research.

1. Technical/Production

Staff and students gained a greater understanding of recording Irish traditional music:

- Three recordings were made utilizing different studio approaches.

- $\quad$ Students documented the microphones and approaches used.

- $\quad$ Researchers identified and addressed the challenges presented by recording different instruments in a studio and other environments.

2. Cultural and aesthetic

Staff and students undertook research on and created arrangements of Irish traditional music:

- Researchers identified and arranged music from various sources for performance and recording, including new compositions by the artists.

- Researchers met with established recording artists to gain insight into their experiences of recording Irish traditional music.

- $\quad$ Producers collaborated with performers and composers to assess the possibilities for arrangement and production.

- Researchers wrote liner notes that provided historical context and other relevant information for the music recorded.

3. Music industry and business 
Staff and students produced an album of traditional music and associated material to industry standards:

- $\quad$ Researchers identified and documented production and postproduction techniques.

- Researchers communicated with industry professionals to ensure album met industry standards and requirements for duplication.

- Material was prepared for dissemination leading to radio airplay and media reviews.

The researchers needed to define the materials of the projects as part of the process. In each of the projects, the collaborative team presented different sound sources. A number of different microphones were trialled to find the desired sound quality. Factors including the size of the recording space, the decision to record some elements in ensemble or isolation, and the presence of some undesirable or less desirable sounds such as button clicks on accordions or fret noises on the banjo, all had to be discussed and resolved. Similar to Zagorski-Thomas' (2014) experiences of recording jazz music, decisions relating to the use of isolation booths or the desire to record instruments in the same space led to compromises between performer comfort and audio quality. There is a desire to capture the ambience of a natural concert performance (or in the case of Irish traditional music, a session), and take advantage of the opportunities presented by a studio space.

An important aspect of the projects and integral to the music programmes at DkIT is a desire to foster and encourage creativity. In recent years, DkIT has emerged as a global leader in creative and aesthetic learning, notably through an Erasmus Intensive 
Programme (CREAL) and the development of a special module in creative collaborative development for incoming first-year students. Creativity was at the heart of the SURP project, bringing together different individuals with diverse experiences and skills to develop a unique sound built upon local and regional music traditions. Following on from previous studies, we recognized that the recording process allowed for critical reflection on artistic creation processes (Pras and Guastavino 2011). For the students this was a valuable experience but, as can be seen from some of the student responses it is only after the completion of the project that students, and indeed staff, recognized the importance of taking time to develop a critical reflection process, particularly given that the participants were not approaching the recording process as a pre-existing band with a well-tested repertoire.

One of the projects facilitated a team of five students, one producer and four musicians, to undertake research and record an album of Irish traditional music that was based on music from the Oriel region in which the Institute is located. Research into local musical traditions is a key strategy of the Centre for Creative Arts Research at DkIT as we recognize our role in recording and analysing the rich cultural and musical traditions of the region in which the Institute is situated. In a concurrent project, two of the supervisory team - Dr Adèle Commins and Dr Daithí Kearney - engaged as performers in a music recording project with a student researcher working as producer on that project. This project provided a useful perspective and experience for the supervisory team through which to empathize and guide students in their projects. The third project involved Commins and Kearney working with another production student to produce recordings of new compositions during the summer of 2016. In all instances, the producer 
had a role in the creative and artistic processes and the performers provided input to the mixing process. The 2016 project led to the release of A Louth Lilt, comprised of new compositions by the musicians.

The process for the projects very much followed the pattern outlined by Hepworth-Sawyer (2009) with different emphasis on the various aspects. The inception very much lay with the supervisory team, who were also the composers on one project. There was limited pre-production with an emphasis on the capturing and forming. This exaggerated the difference in the quality of outputs and quantity of recordings between projects dependent on student versus those with more significant staff input. For two of the projects, post-production periods were extended beyond the initial time frame in recognition of the quality of the work captured. In the final instance, the marketing and distribution processes were taken on by the artists on the supervisory team, with due recognition of the student involvement. Apart from this final stage, all project participants were recognized as producers who had creative control of the recording process (Hepworth-Sawyer and Golding 2011; Moylan 2002).

\section{Oriel Album Project}

For the Oriel Album Project, students undertook the research project for an initial period of five weeks at Dundalk Institute of Technology. The process began with a brainstorming period to gather ideas on ensemble sound, potential repertoire, approaches to recording, technical requirements, followed by listening exercises and rehearsal. Students also had opportunities to meet with local artists and received a visit from singer and collector Pádraigín Ní Uallacháin who has conducted extensive research on the music 
of the Oriel region and recorded an extensive catalogue of material. This allowed them to learn from the passion and experiences of others.

Following the initial development phase, students began recording a number of tracks in the recording studio and recital room. The students explored a number of approaches to recording using isolation and ensemble techniques, as well as click tracks and multitracking, taking time to evaluate the results and refine the recording process. The different spaces used presented different challenges and opportunities to engage with the impact of space on the recordings, use of microphones and subsequent use of audio equalization. Throughout the project, students continued to rehearse the music being recorded, develop arrangements of this repertoire, and explore approaches to recording including microphone placement and selection. By the end of the project there was a significant amount of recorded material to be edited, mixed and mastered.

At this point, upon a critical review of the recorded material an extension of funding was sought and granted to enable the producers to spend additional time completing the final mixes for dissemination. Two students were given extensions to complete the post-production phase of the project. In addition to the action research undertaken, students were required to submit weekly reports, research posters, Sibelius files of arrangements, participant biographies and programme notes for repertoire. For the purposes of developing an educational resource based on research conducted during the project, a tune book with all tunes recorded on the project was collated including a programme note for each piece and a biography for each composer.

\section{The Rose of Ardee and A Louth Lilt}


The recording process for The Rose of Ardee and A Louth Lilt projects was a partnership between lecturing staff who are artists and the students, who had just completed their programme of studies. The first project, undertaken in the summer of 2015, focused on the arrangement of a number of traditional pieces with the engineer having considerable input into the creative process, including performing on some tracks. The engineer's prior interest in the genre was important and she undertook periods of creative development without the presence of the artists. The result was an EP with a mix of approaches but without a coherent sound.

The second project, A Louth Lilt, was recorded in the summer of 2016. It was dependent on prior periods of composition by the artists who had to first collate, share and rehearse their music. Having selected a body of repertoire as a duet, they brought a number of these works to the attention of the co-producer, who had limited experience in Irish traditional music but had completed previous recording projects as part of his undergraduate degree. Due to the limited time, there was not a lot of time to develop the sound for the album, which was instead largely predetermined by the artists, but there was an effort to ensure that all three were engaged in the creative process with periods of experimentation. Both musicians could perform on a number of instruments. As well as piano accordion and banjo, the musicians added mandolin, piano, bouzouki, harpsichord, double bass, bodhrán and percussion. During the recording process, they also experimented with the different sounds and uses of the accordion including the range of voices or reeds and the use of drones.

The principal approach to recording both projects was to close mic both instruments in a single studio room. The musicians faced each other and there was little 
spill. A stereo-pair set-up had been trialled in previous projects but the variety of mics available allowed for closer, more attentive approaches. This approach had implications for editing also. Once the main melody was recorded, additional instruments were added in stages; not all making the final mix as different sounds were accepted or rejected by the creative team.

There was a double-edged challenge for the creative team regarding the sound of the A Louth Lilt album. There was a desire to present the new compositions in a manner that would be appreciated by an audience familiar with Irish traditional music while also considering approaches to recording that borrowed from contemporary popular music. Importantly, the recording did not use a drum kit or guitar, as is usually required by continuous assessment briefs on the BA (Hons) Production of Music and Audio programme. Instead, the bass of the accordion, double bass, piano, bouzouki and percussion were used to fill out some of the spectrum. In a number of instances, it was agreed that the desired sound was sparse, featuring only a single-voice accordion with banjo or mandolin. There is no aspect of the recording that deviates away from this sonic foundation. The sparseness of the sound was itself a challenge for the producer in the mixing process.

Decision making process appropriate to the genre, knowing what is expected within the genre with the realization that this is not fixed and open to debate is further complicated by the fact that what is acceptable within the tradition is not necessarily commercial. There is a realization that older recordings are affected by the limitation of recording and while these recordings are integral to the musicians understanding of their art form, they might not be so useful to the producer. In terms of signal processing, 
corrective processing to address or possibly accentuate sounds such as button sounds or finger screech is used but there is little application of creative processing in traditional music. It is desirable that the producer is silent or, at least, that their input to the production is not immediately noticeable through the use of effects or exaggerated EQ.

That the dynamic range in Irish traditional music does not deviate greatly, in contrast with other genres such as classical music, challenges the approach in production. There is a need to close mic the musicians to capture the intricacies of the genre. For the production students, the projects challenged them to experience tone, timbre and intonation from a traditional music perspective and engage with a different musical form with its own language. While a click track is not the norm in recordings of Irish traditional music, decisions were made on most tracks to use the click track. In some instances, this was a difficult challenge for the musicians who wished to push the rigidity of time in performance as may happen during live performance but it was useful when trying to work vertically on the productions.

Unlike the continuous assessment projects complete during the BA (Hons) Production of Music and Audio programme, many aspects of the projects were prescribed so the focus is on the accurate representation of the instrumentation appropriate to the genre. The producers did not have to create new ensembles from scratch but they did still have input into the desired sound. To do so, they were required to learn how to articulate ideas in a meaningful way for the performers. The performers were also challenged to engage with the language and potential of the production; understanding the difference between recording a representation of a live performance (working horizontally) and 
engaging with the full potential of the studio for creative processes (with a greater emphasis on a vertical approach to production) was important.

\section{Challenges and learning}

Students were prepared in different ways coming from the different programmes and the confidence in their levels of preparation related very much to their primary responsibilities on the project. Following the three dimensions of the project technical/production, cultural and aesthetic, music industry and business - the projects highlighted areas for development in music production education. Each of the producers was confident in their abilities to meet the technical challenges following their studies on the BA (Hons) Production of Music and Audio programme. Recognizing that the project would present a challenge, Sinéad commented 'I felt somewhat prepared. I knew I had the skills, passion and a good chunk of the technological and production knowledge required before starting. I also felt confident in my recording and studio technical skills' (Participant Feedback, 2015). Kenny also noted his familiarity with the facilities and satisfaction with gaining access to the facilities to work on a project like this, '[a]lthough the genre was not necessarily what we studied in the Level 8 [programme], it was directly related in terms of the techniques that we would be using, placing mics and other organisational skills' (Participant Feedback, 2016). In conversation Programme Director Dr Niall Coghlan noted that barriers to production experience are lowering because of accessibility to computer systems and microphones, often these are not high end production technology as was available to the participants at DkIT. The accessibility of these spaces and technology inspired and facilitated creativity and experimentation in production techniques. 
In contrast, many of the performing students were experienced performers of Irish traditional music but had little experience in the studio or of the recording process. The performers noted the opportunity to gain experience in the studio as a positive dimension to the project. Material was also captured in acoustically contrasting locations while exploring various microphone arrangements and production techniques appropriate to the genre. The experiences of the producers in different genres challenged the artists to think beyond their normal creative practices and consider a variety of approaches that could strengthen the production values of the projects. Evelyn reflected a desire to develop in this area stating: 'I wanted to gain more experience in recording, editing, production and being in a studio environment. I also wanted to improve my performance skills as a recording artist and as an arranger' (Participant Feedback, 2015). There was an acknowledgement that approaches to arrangement, which focused on live performance in undergraduate studies, had to be developed in the context of a studio recording.

One of the technical challenges for both musicians and producers related to microphone choice and placement. Horning (2004) notes the importance of microphone choice and placement on the part of the producer as well as the importance of microphone technique on the part of the performer. Responses from Evelyn however highlighted that the performers did not fully understand the importance of microphone placement and the time required to gain optimal results. Echoing Pras and Guastavino (2013), Evelyn noted:

I least enjoyed trying to find the right microphone and position it as it took a lot of time and I was often frustrated by the sound and this then lead to me becoming frustrated and tired when I was recording which then had a negative effect on my playing within the tracks. (Participant Feedback, 2015). 
The performers highlighted the challenge of preparing repertoire to a sufficient standard to be recorded. Evelyn noted:

I did not feel very prepared for this aspect as I felt learning new repertoire in a short space of time and then having to record it would put me under pressure as I didn't think that I would be able to play to as high a standard as would be required in the recording industry. (Participant Feedback, 2015).

The comments from the performers highlight the need for performers to adapt their performance practice to recording (Katz 2004; Blier-Carruthers 2013; ZagorskiThomas 2014; O’Brien-Bernini 2016), which can be aided by a greater understanding and experience of the recording process.

Moving to the cultural and aesthetic dimension of the projects, it was the need to become familiar with the genre of Irish traditional music that was the most significant challenged highlighted by the producers. They desired to become more involved in musical decisions made during recording (see also Horning 2004: 715). John noted: ' $[\mathrm{t}]$ he open access to the studio and recording equipment was invaluable. I wanted to expand my knowledge and experience working within Irish Traditional Music; a genre which I had not worked with before' (Participant Feedback, 2015). Sinead noted:

I was very excited about working on a recording project within the Traditional Irish genre of music - at the time I had only recently re-discovered my passion for it and I was very keen to submerge myself into the project fully. (Participant Feedback, 2015)

The initial research in the projects led to the collation of an archive of music and song of the Oriel Region and new compositions and arrangements of music in the genre of Irish traditional music. Madeline commented that the album allowed the students to have an understanding of the music within the area they are studying and to learn more 
about local composers. Participants also developed their skills in harmony and arrangement with an increased awareness of the opportunities and challenges presented by a studio setting in contrast with a live performance context.

The main challenge related to genre came to the fore in the mixing and mastering process. For many of the production students, there is a focus when completing assignments on contemporary popular music but this project highlighted the potential for production and industry opportunities within Irish traditional music. Developing an appreciation of the genre and tradition, as well as the audience for the recordings being made, was an inherent challenge of the project.

The business aspect of the project required the students to produce not only a technically good and musically competent recording but also one that could be aimed at a particular target market. O'Brien-Bernini's (2016) critical engagement with the marketing of Irish and 'Celtic' music is informative and provides critical reflection on marketing practices in the industry that can inform strategies and discourse for future development. A consistent critique of the recording by both participants and supervisors was that much of the material in student projects did not meet industry standard upon completion despite demonstrating a wide variety of creative ideas, substantial levels of research, and the technical capabilities of the students. This was partly due to poor time management and the lack of experience on the part of the participants in quantifying the time requirements for different aspects of the recording. This was further exasperated by a truncated pre-production period. This resulted in an abundance of raw material at the end of the project without sufficient time to complete the production phase. Sinéad reflected: 
I would have liked to have spent more time honing the album. I really didn't understand the sound/bigger picture until I was actually recording in the studio. This approach has been very different to my previous projects where I had a production sound in my head before starting. This is not to be taken negatively as this was a healthy challenge for me. I feel I definitely could have done better with the resulting mixes - I rushed at the end and I knew my mixes could have been stronger. I was a little bit frustrated that I couldn't get the exact sound I wished at the very end. (Participant Feedback, 2015)

Student responses indicated that this was an important lesson and prepared them well for future endeavours. For Kenny, the project provided a clearer pathway to industry and he suggested that more aspects of business including career guidance in terms of industry roles and opportunities and potentially work-placement could be integrated into the BA (Hons) Production of Music and Audio programme. Building upon feedback already generated from students on the programmes and in line with the teaching and learning ethos in the Department, the projects also emphasized an experiential learning approach and placed a value on creativity.

While the 2015 student projects did not result in a complete album to industry standard, participants developed an understanding of how to approach the recording of an album including the need for consideration of structure and content. The staff recordings benefitted from the experiences of the performers available. A Louth Lilt was released in June 2017, receiving significant national radio airplay in Ireland prior to the launch. From working on the project, Kenny recognized a business opportunity to record and produce Irish traditional musicians and noted the benefit of having a $\mathrm{CD}$ that he could use to promote himself to other traditional musicians and develop his credentials. Similarly Sinéad commented: 
the SURP engaged my passion for recording music and gave me valuable real world experience of working extensively in the studio. The SURP gave me what I felt was lacking from my degree - an extended period of time working in real world music production, getting hands-on experience. Not only did I enhance my skills, knowledge and expertise and gain a greater understanding of Irish music but I grew in confidence personally and in my own abilities. The SURP was an ideal stepping stone between my college life and non-academic life. (Participant Feedback, 2015)

Moving out of the silos of ethnomusicology, performance studies and music production, the projects presented opportunities for the students (and staff) to engage in a broader sense of learning. Creative collaborative development was crucial for the success of the projects as the move from linear to non-linear performance facilitated by reflection and post-performance editorial decisions led to 'a collaborative construction of a composite and partially transformed non-linear performance' (Zagorski-Thomas 2014: 22). Commenting on her involvement in one of the projects, Sinéad noted: ' $[t]$ he format certainly presented me an ideal opportunity to work creatively and apply my skills'. Josephine also noted that one of the benefits of the project was that it allowed her time for creativity, time that was not normally available during semester time. The space and time presented by an intensive research programme outside of term time is an important opportunity for staff and students to explore and develop their creativity, skills and knowledge in a collaborative and productive setting. The programme also made students aware of and prepared them for the potential opportunities for them at postgraduate level including practice-based research.

\section{Conclusion}


The summer recording projects at DkIT were envisaged as an extension of the BA (Hons) Applied Music and BA (Hons) Production of Music and Audio programmes that would allow selected students gain experience in the genre of Irish traditional music and gain industry experience with access to a recording studio for a defined period. All of the participants in the project had an involvement in both performance and production with varying levels of responsibility. This allowed participants to gain an appreciation for the different roles involved in producing an album, developing respect for the need for particular knowledge, skills and decision making. Sinead noted that the SURP aligned well with her degree programme:

[e]very responsibility that I had in the SURP, I had already met in some way during my course through my own research, experience, class-work or studio workshops. Because of the training my course gave me, I was able to engage with the artists, critique and evaluate the music, operate the studio equipment, troubleshoot issues and manage the project efficiently and effectively. (Participant Feedback, 2015)

One of the challenges that Sinead noted was the requirement to work alone, without studio assistants and with limited mentorship. The peer-to-peer review that was inherent in her degree programme when classmates worked together on projects was reimagined through the process of working with artists who were, simultaneously lecturers, which changed the geographies of responsibility in the recording studio (Zagorski-Thomas 2014: 195). Another challenge was the limited time available to create and trial demos to create a particular sound that was new. Thus there were many different sounds created without the establishment of a coherent album sound.

A number of positive outcomes emerged from the projects that were to the benefit of performance and production students. The projects provided staff the opportunity to 
ensure that teaching and research are mutually informing and that course development at undergraduate and postgraduate level is informed by the relevant research activities. Performance students developed improved knowledge of microphone techniques while recognizing both the benefits and limitations of technology in the recording and the postproduction process. Production students gained enhanced knowledge and experience of cultural and creative aspects through engagement in ethnomusicological research and collaboration with performers. Participants, including those already experienced in performing Irish traditional music, also developed a deeper understanding of styles in Irish traditional music, particularly in relation to their own personal styles and how that impacted on their ability to perform and record as part of an ensemble. All participants gained an insight into and respect for the different skills and roles involved in a successful recording project.

\section{Acknowledgements}

We would like to thank the students and colleagues who participated in the projects, and to our colleagues Dr Niall Coghlan and Seán Keegan for their feedback.

\section{References}

Attard, Angele, Di Iorio, Emma, Geven, Koen and Santa, Robert (2010), Student-Centred

Learning: Toolkit for Students, Staff and Higher Education Institutions, Brussels: European Students' Union (NJ1).

Blier-Carruthers, Amy (2013), 'The studio experience: Control and collaboration', in Aaron Williamon and Werner Goebl (eds), in Proceedings of the International Symposium on Performance Science, 28-31 August, Brussels: European Association of Conservatoires, pp. 693-98. 
Commins, Adèle (2014), ‘Paddy Fahey’s and Máirtín Ó hEidhin’s Jigs', A Bunch of Keys, CD, Dublin: Comhaltas Ceoltóirí Éireann.

Commins, Adèle and Kearney, Daithí (2017), A Louth Lilt, CD, Dundalk: Own Label ACDK001.

Creative Ireland Programme (2016), Creative Ireland, Dublin: Creative Ireland, https://creative.ireland.ie/en. Accessed 2 November 2017.

Cronin, John and Kearney, Daithí (2012), Midleton Rare, CD, Cork: Own Label JCDK001.

Deci, Edward L. and Ryan, Richard M. (1985), 'The general causality orientations scale: Self-determination in personality', Journal of Research in Personality, 19:2, pp. $109-34$.

Ellen, Barbara (2017), ‘Ed Sheeran? A busking furby at Glastonbury is so not rock'n'roll', The Guardian, 19 March, https://www.theguardian.com/commentisfree/2017/mar/19/ed-sheeran-headlineslot-glastonbury. Accessed 21 May 2017.

Elliott, David J. (1995), Music Matters: A New Philosophy of Music Education, New York: Oxford University Press.

(ed.) (2005), Praxial Music Education: Reflections and Dialogues, New York: Oxford University Press.

Ganatra, Shilpa (2017), 'Ed Sheeran: "I grew up on Planxty and the Chieftains", The Irish Times, 3 March, https://www.irishtimes.com/culture/music/ed-sheeran-igrew-up-on-planxty-and-the-chieftains-1.2985287. Accessed 21 May 2017. 
Gibbs, Tony (2009), 'Epilogue’, in A. Bayley (ed.), Recorded Music: Performance, Culture \& Technology, Cambridge: Cambridge University Press, pp. 325-32.

Guilbault, Jocelyne (1993), 'On redefining the "local” through world music', The World of Music, 35:2, pp. 33-47.

Halliday, Josh (2017), 'Ed Sheeran singles chart takeover spurs calls for "drastic rethink", The Guardian, 13 March, https://www.theguardian.com/music/2017/mar/13/ed-sheeran-singles-charttakeover-spurs-calls-for-drastic-rethink. Accessed 21 May 2017.

Hepworth-Sawyer, Russ (ed.) (2009), From Demo to Delivery: The Process of Production, Amsterdam: Elsevier/Focal.

Hepworth-Sawyer, Russ and Golding, Chris (2011), What Is Music Production?: A Producer's Guide: The Role, The People, The Process, Oxford: Taylor \& Francis. Horning, Susan Schmidt (2004), 'Engineering the performance: Recording engineers, tacit knowledge and the art of controlling sound', Social Studies of Science, 34:5, pp. 703-31.

IMRO (2015), Report on the Socio-Economic Contribution of Music to the Irish Economy, https://www.imro.ie/news/the-socio-economic-contribution-of-musicto-the-irish-economy/. Accessed 29 October 2017.

Katz, Mark (2004), Capturing Sound: How Technology Has Changed Music, vol. 2, CA: University of California Press.

Kaul, Adam R. (2007), 'The limits of commodification in traditional Irish music sessions', Journal of the Royal Anthropological Institute, 13:3, pp. 703-19. 
Kealy, Edward R. (1974), 'The real rock revolution: Sound mixers, social inequality, and the aesthetics of popular music production', Ph.D. thesis, IL: Northwestern University.

- (1979), 'From craft to art: The case of sound mixers and popular music', Sociology of Work and Occupations, 6:1, pp. 3-29.

Kearney, Daithí (2012), 'Beyond location: The relevance of regional identities in Irish traditional music', Sonus, 33:1, pp. 1-20.

— (2013), 'Regions, regionality and regionalization in Irish traditional music: The role of Comhaltas Ceoltóirí Éireann', Ethnomusicology Ireland, 2\&3, pp. 72-94.

Kolb, David A. (2014), Experiential Learning: Experience as the Source of Learning and Development, NJ: Financial Times Press.

Lawson, Michael A. and Lawson, Hal A. (2013), 'New conceptual frameworks for student engagement research, policy, and practice', Review of Educational Research, 83:3, pp. 432-79.

McCann, Anthony (2001), 'All that is not given is lost: Irish traditional music, copyright, and common property', Ethnomusicology, 45:1, pp. 89-106.

Merrill, Bryce (2010), 'Music to remember me by: Technologies of memory in home recording', Symbolic Interaction, 33:3, pp. 456-74.

Moylan, William (2002), The Art of Recording: Understanding and Crafting the Mix, London: Focal Press.

O’Brien-Bernini, Leah (2016), 'The neoliberalisation of cultural production: An ethnography of professional Irish traditional music', Ph.D. thesis, Limerick: University of Limerick. 
Petridis, Alexis (2017), ‘Glastonbury 2017 verdict: Radiohead, Foo Fighters, Lorde, Stormzy and more', The Guardian, 26 June, https://www.theguardian.com/music/2017/jun/26/glastonbury-2017-verdictradiohead-foo-fighters-lorde-stormzy-and-more. Accessed 20 October 2017.

Pras, Amandine and Guastavino, Catherine (2011), 'The impact of producers' comments and musicians' self-evaluation on performance during recording sessions', 131st Audio Engineering Society Convention, New York, NY USA, 20-23 October. (2013), 'The impact of producers' comments and musicians' self-evaluation on perceived recording quality during recording sessions', Journal of Music, Technology and Education, 6:1, pp. 81-101.

Seymour, Henry (1918), The Reproduction of Sound: Being a Description of the Mechanical Appliances and Technical Processes Employed in the Art, London: W.B. Tatters.

Snapes, Laura (2017), 'Ed Sheeran has 16 songs in the top 20 - and it's a sign of how sick the charts are', The Guardian, 10 March, https://www.theguardian.com/music/musicblog/2017/mar/10/ed-sheeran-has-16songs-in-the-top-20-and-its-a-sign-of-how-sick-the-charts-are. Accessed 20 October 2017.

Thibeault, Matthew D. (2012), 'Wisdom for music education from the recording studio', General Music Today, 25:2, pp. 49-52.

Various artists (2015), 'Wake up the World', Journey to Your Heart, compilation CD, Marie Dunne CHF. 
Walzer, Daniel A. (2015), 'Critical listening assessment in undergraduate music technology programmes', Journal of Music, Technology \& Education, 8:1, pp. 41-53.

Zagorski-Thomas, Simon (2014), The Musicology of Record Production, Cambridge: Cambridge University Press.

\section{Note}

1. Developed from a paper presented at the Music Production Education

Conference, York St John University, York, United Kingdom, Thursday 29 June 2017.

Daithí Kearney and Adèle Commins have asserted their right under the Copyright,

Designs and Patents Act, 1988, to be identified as the authors of this work in the format that was submitted to Intellect Ltd. 